This item was submitted to Loughborough's Research Repository by the author.

Items in Figshare are protected by copyright, with all rights reserved, unless otherwise indicated.

\title{
The effectiveness of the World Anti-Doping Agency: developing a framework for analysis
}

PLEASE CITE THE PUBLISHED VERSION

https://doi.org/10.1080/19406940.2018.1534257

\section{PUBLISHER}

(C) Taylor \& Francis (Routledge)

\section{VERSION}

AM (Accepted Manuscript)

\section{PUBLISHER STATEMENT}

This is an Accepted Manuscript of an article published by Taylor \& Francis in International Journal of Sport Policy and Politics on 14 November 2018, available online:

http://www.tandfonline.com/10.1080/19406940.2018.1534257.

\section{LICENCE}

CC BY-NC-ND 4.0

\section{REPOSITORY RECORD}

Houlihan, Barrie, and Dag V. Hanstad. 2018. "The Effectiveness of the World Anti-doping Agency: Developing a Framework for Analysis”. Loughborough University. https://hdl.handle.net/2134/34346. 


\section{The effectiveness of the World Anti-Doping Agency: developing a framework for analysis}

\section{Barrie Houlihan and Dag Vidar Hanstad}

Twenty years on from the establishment of WADA the Agency lies at the centre of a complex network of organisations. Over 500 international sport organisations (ISOs) have incorporated the Code into their rules and over 170 countries have ratified the UNESCO Convention that requires governments to enforce the Code. However, despite the rapid endorsement of the Code doping persists as a major problem in international sport. The ability of some athletes, such as Lance Armstrong, to evade detection for so long, the consistent ineffectiveness of anti-doping processes in major sporting countries such as Kenya and Jamaica, and institutionalized doping discovered during the 2014 Sochi winter Olympic Games are among a number of recent episodes that suggest that the global anti-doping policy regime is still struggling to cope with the scale and nature of the problem. Furthermore, while data from WADA (WADA 2008, 2017) indicate that the number of adverse analytical findings has remained relatively stable in recent years (1.4\% in 2007, 1.2\& in 2015 and 1.5\% in 2016) academic research has suggested that these figures are a serious under-estimate of the true level of PEDS use. For example, Striegel et al (2010: 230) in a study of doping in Germany concluded that 'data from official doping tests under-estimated the true prevalence of doping in elite sports by more than a factor of eight' (see also Pitsch \& Emrich 2012 for a similar conclusion). In a review of a range of methods of measuring the prevalence of doping de Hon et al (2015: 57) concluded that 'a combination of questionnaires using the Randomised Response Technique and models of biological parameters ... yield an estimate of $14-39 \%$ of current elite athletes who intentionally used doping'.

There are a number of possible explanations for the apparent lack of regime effectiveness including scientific advances in doping, such as 'designer drugs' (see Mazzoni 2017, Mottram 2018), under-resourcing of anti-doping activity in 
some countries (WADA 2013, House of Commons 2018), obstruction in some countries including Brazil (Reuters 2016, WADA 2016), Kenya (Guardian newspaper 2016) and Jamaica (WADA 2013), and the duplicity of some governments and international federations (WADA 2015, IOC 2017). The lack of commitment by key stakeholders (defined in this paper as the summer and winter international federations and the countries that rank in the top 30 in the summer Olympics and top 10 in the winter Olympics) was highlighted in a recent WADA review of progress in combating doping (WADA 3: 2013) which concluded that:

The primary reason for the apparent lack of success of the testing programs does not lie with the science involved. ... The real problems are the human and political factors. There is no general appetite to undertake the effort and expense of a successful effort to deliver dopingfree sport.

If the definition of key stakeholders is restricted to those countries that rank in the top thirty of the summer Olympic medals table then at least six of them (Russian Federation, Brazil, Spain, Kenya, Jamaica and Kazakhstan) have been subject in recent years to challenges by WADA regarding their depth of commitment to anti-doping. The concern with the lack of commitment was echoed at the 2018 conference, Clean Sport = Fair Outcome?, held in Oslo ${ }^{1}$. Richard McLaren referred to the 'lack of will' among stakeholders and commented that doping in sport was for many stakeholders 'an inconvenient truth'. Travis Tygart ${ }^{2}$ claimed that WADA was 'controlled by sport' and that the IOC believed that 'it had weathered the storm' of the Russian scandal. The former minister for sport from New Zealand, Clayton Cosgrove, accused the IOC of trying to weaken the terms for Russian readmission to the Olympic Games and suggested that WADA was 'at a crossroads [due to] attacks by the IOC and international federations'. A constant theme of the conference was the conflict of interest primarily among international sport organisations,

1 The quotes are from notes taken at the conference that was attended by both authors.

${ }^{2}$ CEO of US Anti-Doping Agency 
but also evident among governments in being responsible for leading WADA and also promoting their sport, event or country.

However, it may also be the case that part of the explanation for the growing concern with the rate of progress in policy implementation is that stakeholders have been encouraged to adopt unrealistic expectations of the capacity of WADA and the anti-doping network to tackle the problem and that WADA and other key policy actors have over-promised - raising expectations that cannot be fulfilled. While a commitment to produce a 'crime-free' society would be treated as grossly naïve there is regular and frequent reference to 'dopingfree sport' on the WADA website and in the Code. However, it may also be the case that part of the problem of perceived under-performance of the antidoping regime lies with WADA itself and whether the Agency is effective in its crucial role as lead policy actor on doping in sport.

The aim of this paper is to develop and operationalize a framework for the analysis of the effectiveness of WADA. The paper begins by situating the study of international organisatons (IOs) within analyses of regime effectiveness and within debates about the significance of IOs in current international relations theory. This discussion is followed by a review of the literature concerned with assessing organizational performance and effectiveness which provides the foundation for the development of the framework for the analysis of 10 effectiveness. The framework distinguishes between internal or structural factors and contextual factors that affect IO effectiveness. As each factor is defined it is applied to WADA providing a profile that forms the basis for the overall assessment of the Agency.

\section{Power, politics and international organisations}

Most studies of policy focus either on the impact of policy (have the objectives been achieved) or the effectiveness of the policy regime (the collection of organizations and underpinning values central to the policy) rather than the performance and effectiveness of key IOs. Studies of sport policy are no 
different with the majority focusing on the effectiveness of the policy (Kayser et al 2007) or the effectiveness of the policy regime (Houlihan 1999, 2014; Hanstad et al 2010). As Biermann and Bauer (189: 2004) note 'few scholars have yet attempted to systematically examine the effectiveness of international organizations (IOS) as actors in their own right' (see also Lall 2017 and, for an exception, see Hanstad et al 2008). Not only does this neglect tend to over-emphasize the role of the state, but it also undermines attempts to analyze regime strengths and weaknesses. At this point in the discussion it is important to distinguish between IO performance and IO effectiveness. Performance is best defined as efficient use of resources to produce positive outcomes and effectiveness as the achievement of IO objectives. The importance of this distinction is indicated by Gutner and Thompson who note 'that well-functioning internal processes do not necessarily imply that an entity will fulfill its goals. The expectation may simply be too great or the organization's goals too difficult to achieve. By the same token, if goals are easy to achieve an entity might succeed perfectly well even when its performance is not very impressive' (2010: 232).

In general, much of the research into effectiveness of IOs tends to be critical focusing on the pathology of IOs. Particular emphasis is given to the assumed tendency of IOs to exercise power in ways that were unintended by the organisations (usually states, but in the case of WADA also international sport organisations) that granted them authority. Indeed Barnett and Finnemore (699-700: 1999) refer to the 'propensity for dysfunctional, even pathological behavior' of IOs such that they can become 'unresponsive to their environment, obsessed with their own rules at the expense of primary missions'. Vaubel and Dreher (2004) add weight to this critique and suggest that weak IO performance is due to the rent-seeking behaviour of IO officials who succumb to the moral hazard and use their autonomy to pursue their own goals. However, Lall (248: 2017), while acknowledging the problem of poor IO performance, argues that the 'primary obstacle to effective 10 performance is not deviant behavior by international bureaucrats ... but the propensity of states to use IOs to advance their narrow national interests rather than broader organizational objectives'. Implicit in Lall's observation is the view that 
a key characteristic of an effective 10 is autonomy, but de facto rather than simply de jure autonomy. Lall also argues that the moral hazard problem is more acute for principals (which, in the case of WADA, are states and ISOs) than for agents (i.e. WADA). As agents need to retain legitimacy in the eyes of principals any pursuit of self-interested goals is constrained by the acknowledgment that 'performance [i.e. fulfillment of organizational goals] is the path to legitimacy' (Gutner and Thompson 2010: 228). In contrast the collective action problem (doping in sport) that led principals (states and ISOs) to agree global regulations (the Code) are likely, as time passes, to consider the rules and the enforcing agents a constraint on their pursuit of self-interest. As Lall (2017: 252) observes this 'shift in incentives leads to a suboptimal equilibrium in which IOs - torn between national and collective interests - fail to realize organizational objectives'. The risk of pathological behaviour by IOs and their vulnerability to pressure from key stakeholders emphasizes the importance of analyzing their role in the policy process and in maintaining regime integrity and momentum. Equally important is the recognition that not all IOs exhibit pathological behaviour.

From the foregoing discussion there would appear to be three important and related aspects of IO behaviour: first, the extent to which they are independent policy actors (Krasner 1983, Niskanen 1971) and not simply an arena for stakeholder politics (Waltz 2000); second, the power that they possess, the sources of that power and how it is operationalized (Risse 1995, Checkel 2005); and third, and of particular relevance to this paper, the extent to which IOs make a positive contribution to addressing the collective action problem that led to their establishment (Stokke \& Hønneland 2007, Rittberger et al 2012, Costa \& Jørgensen, 2012). According to the neorealist perspective on international relations IOs are creatures of states (or in the case of WADA states and ISOs) because if they were not what motive would stakeholders have for establishing them? IOs are established to help states overcome collective action problems and are designed to produce mutual benefits. While many ISOs clearly produce benefits for most if not all states (for example, regulation of the international postal and telephone services, air transport, and radio waveband allocation) others may be the outcome of a compromise 
between mutually suspicious/antagonistic stakeholders suggesting that what is significant is not the effectiveness of the IO but 'what they represent symbolically and the values they embody' (Barnett and Finnemore 703:1999). Consequently, the extent to which IO actions are, whether consciously or unconsciously, the direct product of the aggregation of member state preferences needs to be acknowledged (Abbott and Snidal 1998, Garrett et al 1998). According to this view IOs are structures rather than agents capable of purposive political action and are best seen as 'empty shells or impersonal policy machinery to be manipulated by actors' (Barnett and Finnemore, 1999: 704).

Neoliberal institutionalism takes a different view arguing that IOs are intervening variables with a capacity for independent agency and are important in solving collective action problems. The resources that IOs possess, especially specialist knowledge, enables them to mediate between conflicting stakeholders. However, neoliberal institutionalists still argue that the degree of IO autonomy is constrained. As Barnett and Finnemore (1999: 704-5) argue 'Although this line of scholarship accords IOs some causal status (since they demonstrably change outcomes), it does not grant them autonomy and purpose independent of the states that comprise them'. As Lall (2017: 250) notes what both perspectives have in common is the functionalist assumption that IOs 'do provide the benefits desired by their creators'.

Empirical studies of the functioning of IOs tend to challenge the assumptions of the realists and provide some support for the neoliberal perspective. Research suggests that IOs can exercise considerable autonomy resulting from their accumulated knowledge and expertise and the legitimacy granted to them by stakeholders. According to Barnett and Finnemore (1999: 710) IO's autonomy is based on three sources: the power to classify; the power to fix social meanings; and the power to express and diffuse new norms and values. A defining feature of bureaucratic organization is the ordering and classification of information. 'The ability to classify objects, to shift their very definition and identity, is one of bureaucracy's greatest sources of power' (1999: 710). WADA's publication of the Code and the annual publication of 
the list of prohibited substances and practices is evidence of considerable power of classification. Substances are classified as prohibited or permitted, countries are classified as compliant or non-compliant and laboratories are classified as accredited or non-accredited. WADA also 'fixes meanings', particularly such value-laden concepts as the 'spirit of sport', 'play true' and 'doping-free sport'. These meanings not only legitimize WADA's activities, but also provide the ideological reference points within which norms are generated and against which the actions of stakeholders are judged. The final source of IO autonomy follows from the power to fix meanings and concerns the diffusion of norms. As Barnett and Finnemore (1999: 713) observe 'Officials in IOs often insist that part of their mission is to spread, inculcate, and enforce global values and norms. They are the "missionaries" of our time'.

\section{Assessing organizational performance and effectiveness}

Studies of organizational performance and effectiveness often focus on some combination of outputs, outcomes and impact. Outputs are primarily concerned with performance and can be defined as the activity of the organisation and would include the Code and the associated set of International Standards and processes generated by WADA. Central to the assessment of outputs is the efficient use of resources and, for WADA, would include the production of information and educational materials and compliance monitoring systems (data collection and analysis). However, it must be borne in mind that the efficiency of an $\mathrm{IO}$ is not always completely under the control of the IO. For example, the analysis of data for compliance monitoring purposes often relies on stakeholders providing accurate and timely data. Finally, as mentioned above high quality output performance does not guarantee outcome and impact effectiveness. As Gutner and Thompson observe 'At best, process performance is a necessary but not sufficient condition for favorable outcomes' (2010: 236). Furthermore, it is often difficult to provide evidence of a causal relationship between outcomes and efficient performance at the output level. 
Outcomes can be defined as the changes in behaviour of primary stakeholders such as the governments that have signed the UNESCO Convention and the ISOs that have incorporated the Code into their rules. Here the focus is on determining the extent to which ratification has resulted in compliance, that is, enthusiastic commitment to the objectives of the Code and WADA (Houlihan 2014). Measurement is problematic, but one approach to identifying enthusiastic commitment is to analyse the allocation of resources by major 'sports powers' (broadly those in the top 30 positions in the summer Olympic medals table and top 10 in the winter Olympics medal table, the Olympic federations and the major commercial federations). Provision of money, scientific expertise and facilities, and administrative support would indicate commitment as would the number of tests conducted, the response to adverse analytical findings, the introduction/amendment of regulations controlling access to PEDS and active involvement and support for international anti-doping activities (facilitating the work of International Observers, attending/hosting anti-doping workshops/conferences. Another, but more challenging, approach might be counterfactual analysis that would explore the extent to which behaviour would have differed had the Code not been in place. Finally, impact is the change in the target problem. However, the problems associated with calibrating secretive activities such as doping are readily acknowledged (Stubbe et al 2014, de Hon et al 2015).

Even when clarity (or at least agreement) regarding definitions of outputs, outcomes and impact has been achieved there still remain a number of problems when assessing 10 performance and effectiveness. First, and particularly problematic in relation to doping, is the issue of measurement of progress towards IO objectives. Leaving aside the tendency of IO evaluation to focus on measuring outputs rather than outcomes and impact agreeing robust measures of impact is extremely challenging. If the number of doping violations is taken as a key measure an increase or decrease in the number of doping violations could be interpreted both positively and negatively. An increase in the number of recorded doping violations might indicate a worsening problem and 10 failure, but it might also indicate greater 10 effectiveness in detection. Similarly a decrease in recorded violations might 
indicate a reduction in the use of PEDS or simply that athletes are using currently undetectable 'designer' drugs or that their domestic NADO is colluding in the doping process. A second problem of measurement concerns determining the period within which a policy should be effective. All policies have a time lag between their introduction and the point at which an effect is (or should be) discernible. For example, the effect of a decision to eliminate all sport from the school curriculum should be evident within one academic term whereas a policy to reduce by $50 \%$ childhood obesity would take considerably longer - but how much longer is difficult to determine. A third problem is agreeing the specific metrics to be used to measure progress. Should greater weight be given to the reduction in the use of particular PEDS (steroids use reduction given greater weight than reduction in the use of beta-blockers for example) or to the reduction in particular competitions (the Olympic Games for example) or in particular categories of sport (highly commercial in preference to non-commercial)? Finally, the discussion and measurement of outputs, outcomes and impact is flawed if equal attention is not given to the quality and quantity of inputs. There are many examples of international agreements that remain at the aspirational level because of the neglect (whether unintentional or deliberate) of the resource base.

\section{A framework for analyzing the organizational effectiveness of WADA}

From the foregoing review it is evident that 10 performance and effectiveness are influenced by two sets of factors - one internal or structural and the other external or contextual. While the specific range of factors and their relative importance will vary from one $1 \mathrm{O}$ to another internal factors will tend to be a mix of regulatory/legal, cultural and organizational while the external factors will usually be a mix of political, economic and scientific. In relation to WADA we suggest that key internal or structural factors include: the formal competencies granted to the 10 and the clarity of the IO mission; the degree of regime embeddedness and exclusivity; organizational cohesion and design; leadership quality; resource availability; and stakeholder involvement. The main external or contextual factors include: scientific or technological 
developments; economic developments; position on the policy agenda and competing policy concerns; the cost/benefit of political support; and public attitudes.

\section{Internal/structural factors}

The formal competencies granted to an organization refers to the transfer of responsibilities and authority from states or other powerful policy actors. In the case of WADA the focus would be on the extent to which states have granted WADA authority over their national sport system. Examples might include the certification of domestic laboratories for testing doping samples, the acceptance and support of independent observers at sports events hosted in the country and the right of doping control officers to conduct no notice out of competition tests on national athletes. A similar analysis would be required of the extent to which international federations (IFs) and event organisers, such as the IOC, have granted WADA competencies that impinge on their traditional areas of autonomy, especially the relationship between IFs and their athletes. The extent to which stakeholders grant and respect the autonomy of the $\mathrm{IO}$ is central to IO performance. In many studies of IOs a recurring problem is the reluctance of states and other stakeholders to respect the autonomy that they may have previously granted to the IO (see for example, Talberg 2016, Lipson 2010, Elsig 2010).

With regard to WADA the transfer of responsibilities was easier to achieve than the transfer of authority. The establishment of WADA was, for many countries and sports a way of off-loading responsibility (and a degree of accountability) for an increasingly inconvenient and intractable issue. However, the transfer of responsibility was not matched by a similar transfer of authority. The IOC along with many governments and IFs have consistently undermined the authority of the Agency either through deliberate sabotage (as in the case of Russia and the IAAF) or by ignoring their obligations under the Code (as in the case of the IOC awarding the Olympic Games to Brazil despite a critical Independent Observer report on the earlier Pan-America 
Games, having its laboratory accreditation withdrawn and having seriously under-invested in its domestic anti-doping programme).

The clarity, stability and realism of the mission of the IO are also important factors. Edwards, discussing the work of human rights NGOs, argues that 'The objectives must not be so broad as to be unattainable, such as a mission to eradicate all human rights violations [nor] overly narrow' (Edwards 2010: 194-5). Furthermore, many IOs have multiple objectives and it is important that they are broadly compatible. For example there is an awareness that the agencies concerned with pursuing the UN sustainable development goals often find that 'development' can conflict with 'environmental sustainability' (Charnovitz 2005). WADA's mission is ostensibly clear being 'to lead a collaborative worldwide movement for doping-free sport' and has remained largely unaltered since the establishment of the Agency. However, the clarity is more apparent than real as there has been a continual dispute between WADA and it major stakeholders and also within WADA regarding its primary mission and where the boundaries of its mission lie. The IOC has on a number of occasions rebuked WADA for exceeding its competence most recently in telling the IOC how to respond to the Russian government's organised doping at the Sochi Olympic Games. There are also internal tensions regarding the primary mission of WADA and particularly whether it is to monitor compliance with the Code or also to provide a set of services such as education and research. Furthermore, while it can be argued that the clarity and stability of the mission is undermined by a lack of realism insofar as doping-free sport is no more achievable than crime-free society the counter argument is that mission statements tend to be aspirational and overambitious and function as an inspirational framework for action. A mission to 'slightly reduce doping in sport' might be more realistic, but is not likely to generate resources and long-term commitment from stakeholders.

With regard to the degree of regime embeddedness and exclusivity. Regime embeddedness refers to the extent to which the $\mathrm{IO}$ is acknowledged as being central to the policy regime. For example, in relation to disability sport the International Paralympic Committee is the highest profile organization in the 
policy regime, but as the Paralympic Games offers opportunities to only a limited range of disabilities its degree of embeddedness is modest. By comparison in the policy regime concerned with the rights of children the leadership role of the UN is widely acknowledged. Regime exclusivity refers to the extent to which the 10 faces competition for regime leadership. As Vatterodt (2008) argued in her analysis the implementation of the Paris Declaration on Aid Effectiveness one of the main barriers to greater effectiveness was the number of overlapping UN agencies with an involvement in delivering the Millennium Development Goals (see also Graham 2011). Uncertainty regarding remit and organizational territory inhibits effective strategy development and use of resources. With regard to WADA it is not clear whether the Agency occupies a highly contested or a partly abandoned policy space. On the one hand the IOC still seems unwilling to accept the loss of policy leadership at the 1999 Lausanne conference when Samaranch's suggestion of a global anti-doping organization constituted as an IOC commission was rejected. The IOC's lack of support for WADA is best illustrated by the Committee's failure to accept WADA's recommendation that Russia should be banned from the 2016 Olympic Games despite clear evidence of institutionalised doping. More recently, the IOC made a series of proposals for a "more robust, more efficient, more transparent and more harmonised" anti-doping system ${ }^{3}$ The proposals subtlely undermined WADA in the guise of offering support and suggestions for strengthening the antidoping regime. However, the IOC organised the retesting of over 1000 samples from the Beijing and London Olympic Games resulting in over 100 positive results being identified. The IOC appears to be torn between supporting WADA and seeking to regain its lost policy leadership (Wagner and Petersen 2014). A reluctance to grant WADA exclusive regime leadership is not confined to the IOC for as Wagner (2011) points out commercially successful sports, including football and road cycling, dragged their heels in accepting the Code and have continually sought special treatment in terms of sanctions on their athletes. The attitude of the IOC and some of the major IFs

3 IOC seeks to reform anti-doping with 'more robust' WADA, Available from: https://edition.cnn.com/2016/10/08/sport/ioc-anti-doping-proposalswada/index.html , CNN, accessed 28 $8^{\text {th }}$ March 2018 
is balanced to an extent by the strong support WADA has received from some states including France, Australia, Germany, Canada, Norway and the United States. WADA's institutional alliances have helped the Agency protect its autonomy from erosion by subversive states and IFs and has also offered the Agency material help in pursuing doping violations (most notably the US government's Federal Bureau of Investigation).

The organisational cohesion of the agent cannot be assumed. While it is common in principal-agent research to take account of the likely fragmentation among collective principals such as states there is often an assumption of value homogeneity and structural integration at agent level. Yet, as Graham (367: 2014) noted the assumption of agent unity 'is an empirical question rather than ... a given'. The assumption of unity is more fragile when the agent is organizationally fragmented as when responsibility is dispersed across a network of regional or national offices. Moreover, 10 culture over the longer term is the product of a range of factors including the experience of operating in the field, the values carried into the organization by professionals (such as doctors, scientists, sports administrators, police and customs officers). Most IOs rely on effective socialization by senior management into the core values and norms of the organization. In many cases this strategy is effective largely because those who choose to work for or with the $1 \mathrm{O}$ are often self-selecting due to their sympathy for the $1 \mathrm{O}$ objectives. However, the capacity of senior management to control the socialization process is sometimes limited either by competing sources of values (such as organized labour and professional bodies) or by the scale of the organization and the tendency for large bureaucracies to specialize and compartmentalize and, as a consequence, develop discrete value systems which may or may not reinforce the core organizational values (March and Olsen 1989, Shien 1996). However, where policy implementation relies on more general administrative agencies or a large dispersed network of outposts reliance on the 'soft incentive' of socialization is less effective. Pollack and Hafner-Burton (2010) argue that in some cases 'hard incentives' (for example, financial rewards or the award of hosting rights to major sports events) are required to ensure commitment. 
WADA is a small 10 with 88 staff of whom 74 are at the Montreal headquarters and 14 spread over four regional offices. Of the current staff 24 have been in post for over 11 years and 14 for over 6 years. Given the small staff complement, the high proportion of long servicing staff and the colocation of over $80 \%$ of staff the Agency should find it easier to maintain value cohesion among staff and maintain close intra-organisational communication ${ }^{4}$. However, the maintenance of value cohesion among staff and among board and committee members perhaps comes at the cost of the Agency's global ambitions. The composition of its staff and of its decisionmaking and advisory committees and boards is highly skewed. For example of the fourteen senior WADA staff ten are either from North America or Europe. With regard to the board and committees Hein Verbruggen, past President of the $\mathrm{UCI}$ and IOC Honorary Member, in a letter to Thomas Bach ${ }^{5}$ in 2016 pointed out that: 'there are 11 WADA committees and 9 of them are chaired by people from Anglo-Saxon countries ...; there are in total 112 members and 56 of them are from Anglo-Saxon countries and 10 are from Scandinavia; from the 11 committees, 7 have a majority of Anglo-Saxons and 2 more have a majority of Anglo-Saxons and Scandinavians...'. Although Verbruggen was using these data to suggest an anti-IOC bias in WADA the data could also indicate that the organizational value cohesion is one that is constructed as much through the exclusion of dissenting voices and valuesystems as through normative socialisation.

Related to the question of organizational cohesion is the issue of organisational design which refers to the degree of structural flexibility or adaptive capacity i.e. the capacity to respond to changes in the IO's operating context and which is often seen as a correlate of effectiveness as more

\footnotetext{
${ }^{4}$ IOs vary greatly in size as measured by paid staff. The UN has around 44,000 staff and the World Health organization 7000. The paid staff of WADA in 2016 numbered 88 of which 74 are at its Montreal HQ. The OECD defines a small to medium sized enterprise as having fewer than 250 employees.

${ }^{5}$ Fancy Bears leak reveals IOC concerns at WADA's alleged Anglo-Saxon Bias. Available at: https://sputniknews.com/sport/201801151060774639verbruggen-letter-to-ioc-chair-on-wada-bias/ Accessed: 28 ${ }^{\text {th }}$ March 2018
} 
hierarchical IOs tend to be slower to respond to changes in the environment. WADA operates within an extremely complex and dynamic policy environment. The complexity is well recognized while the dynamism is best illustrated in relation to the rapidly innovation in PEDS development and use and in the pressure on WADA to expand its remit beyond detection of use by athletes to include issues of manufacture, trafficking and supply and the role of the athlete's entourage. In broad terms WADA has been reasonably nimble in responding to these changes. The list of prohibited substances and practices is updated annually and the core policy document, the World AntiDoping Code, is reviewed and revised on a roughly four year cycle.

The quality of IO leadership is the 'ability of the organizational leaders to inspire, prioritize, make decisions, provide direction, and innovate' (Despard 2017: 609) and refers not only to the leadership by paid staff (CEO, COO etc.), but also to the leadership provided by the board of the organization. A recurring problem in many IOs is the lack of continuity and interest taken in the work of the 10 by board members especially if membership is based primarily on representing stakeholders. Many IO boards are characterized by a regular turnover of governmental representatives (whether public officials or elected representatives) and the under-representation of countries in the global South (Andresen 2007, Kaasa 2007). WADA shares many of these generic problems. While it has benefited from high profile leaders, most notably Richard Pound, and from a low turnover of senior staff it has suffered from a constantly changing set of political appointees to its Foundation Board in contrast to the relative longevity and stability in Olympic Movement appointees. Not only does the impermanence of political appointees to the Board weaken the relationship between WADA and key stakeholders, but it also means that aspects of governance are also weak, especially in relation to accountability (and the accumulated organizational knowledge that is an integral part of accountability) and to prioritization and the provision of direction. Five years after the establishment of WADA, Hans B. Skaset, who was a member of the Norwegian delegation at the Lausanne Conference as Director General in the Ministry of Culture, stated that governmental representatives would continuously be at risk of being taken hostage by the 
Olympic Movement (Skaset, 2004). There is little evidence that that threat has receded.

The availability and character of resources refers to the range of the resources required, their volume and quality, and the process by which they are transferred to the IO. Resources include: access to states and to state level policy actors and whether access was direct or mediated by the state; access to 'subjects' and whether access was restricted or open; access to knowledge held by other policy actors and whether access was open, by payment or by exchange; expertise/knowledge, especially whether the IO had the resources to generate scientific knowledge and intelligence independently or only through reliance on other actors; finance, particularly the quality and volume of finance indicated by the ease of collection, whether contribution is mandatory or voluntary, whether the donor community is large or small and whether the volume was sufficient for the IO's responsibilities.

In terms of access WADA has had mixed experience. Access to governments, IFs and the IOC is partly direct (through national or sport organization antidoping organisations) and partly though representatives on the Foundation Board. Access to WADA's 'subjects' (athletes) is more problematic as there is much evidence of variability in the maintenance of whereabouts data (Hanstad and Loland 2009) and of obstruction and lack of cooperation from event organisers in accessing athletes for testing (WADA 2011, WADA 2012). With regard to access to knowledge the Pound Report (WADA 2012: 6) noted:

- Active interference in the effectiveness of anti-doping activities (e.g. data protection issues continually raised by a small group of civil servants ...

- Unwillingness to share doping-related information (more blessed to receive than to give)

- Some governments have impeded the investigation and follow-up on doping activities as well as sharing information (e.g. Operation Puerto) Finally, WADA complains of the serious under-funding of its activities. One of the most effective ways of undermining the legitimacy of an organization is to 
burden it with an ambitious mission (drug-free sport) and then starve it of sufficient resource. As the Pound Report (WADA 2012: 6) observed there have been 'Universal calls for increased activities by WADA, coupled with demonstrated unwillingness to provide adequate resources'.

Stakeholder involvement. Studies of policy-making and implementation indicate that the level of stakeholder involvement (for example, indicated by participation in congresses, conferences and workshops, secondment of staff, regular interaction on policy matters) is positively correlated with ease of policy implementation. Management research suggests that stakeholder involvement generates a perception of procedural justice that legitimizes policy and the actions and decisions of the IO (Thibaut and Walker 1975, Konovsky 2000, Dembinski 2017). Consequently, the resources invested in maintaining and managing stakeholder relations is considered to make a substantial contribution to IO effectiveness. It is in this respect that WADA experiences significant weakness. Among the key stakeholders for WADA governments, IFs and the IOC - there are few that could be described as enthusiasts for anti-doping. For the vast majority 'Instead of WADA being recognized as the leader in the fight against doping in sport and supported by the stakeholders, it is viewed as an irritant' (WADA 2012: 2). According to WADA Vice-President, Linda Hofstad Helleland 'The public see fighting. Not against doping, but against each other' 6 . 'As WADA has moved from its formative stages to the ongoing fight against doping in sport, ministerial enthusiasm has waned and fewer Ministers are attending the WADA meetings. Whatever political appeal anti-doping may have had seems to have worn off and more and more states now send civil servants as their representatives' (WADA 2012: 5-6).

Contextual factors

${ }^{6}$ Reforms take centre stage at WADA symposium. Available at: http://www.sportsintegrityinitiative.com/reforms-take-centre-stage-wadasymposium/. Accessed on: $20^{\text {th }}$ July 2018 
Many IOs operate within a context where science and scientific developments are central to their activity. For some medical aid agencies or technologyfocused economic development IOs the issues might be the transferability of science from one country/culture to another or the availability of local resources to absorb and exploit technology. For other IOs, such as Greenpeace and Privacy International ${ }^{7}$, the policy and campaigning environments within which they operate are dominated by rapid scientific and technological change - climate science for the former and data gathering technologies for the latter. For all these IOs their capacity to track, understand and respond to scientific change is crucial for the fulfillment of their missions. WADA operates in a highly dynamic scientific environment. First, the scientific environment is dominated by a large number of extremely wealthy pharmaceutical businesses that have no direct interest in sport or doping, but who are competing for a share of the lucrative therapeutic medicines market. All PEDS have a significant therapeutic market and scientific innovation is an essential aspect of the competition for market share. The constant refinement of drugs for therapeutic use (particularly EPO and steroids) poses serious problems for WADA due to the need to keep abreast of variants (produced by major pharmaceutical companies or by the growing number of small companies who specialize in modifying the scientific signature of drugs popular with athletes to make them less easy to detect) and to develop reliable assays. Cooper (2012: 37) refers to recent scientific development in the treatment of cancer recovery and heart attack with derivatives of EPO that have produced 'economic drivers that exist for the development of new generation of performance enhancing drugs'. He also mentions the progress in developing 'smart drugs' to combat Alzheimer's disease that might be exploited to improve cognition and decision-making. In addition to the pace of innovation in broadly conventional drugs there is the prospect of gene doping on the horizon. Although there are no confirmed cases on athletes using gene doping there is little doubt that there is interest among athletes in the potential of the science. With over 2000 current clinical trails in progress it would appear to be only a matter of time before WADA will be involved in meeting

\footnotetext{
7 Privacy International seeks to challenge and limit state and corporate surveillance and protect personal privacy
} 
the challenge of gene doping. As Friedman et al (2010: 648) noted 'The global marketplace is ready to meet the demand in ways that will inevitably include untested, and perhaps unregulated, products ...'.

With regard to the economic context of IO activity one key aspect is the stage of the global economic cycle which will affect the ability and willingness of donors to fulfill their obligations to the IO. A second aspect of the economic context is change in the balance of financial resources between stakeholders involved in or targeted by the policy regime. WADA is dependent on funding from states and from international sport organisations. Generally WADA has been successful in receiving over 95\% of expected income (of just under \$30m USD in 2017), but has been far less successful in encouraging states and ISOs to increase their contributions. Indeed according to the Pound Report many state representatives on the Foundation Board 'seem to measure their organizational success by how they are able to limit increases in budget contributions or to reducing such contributions, rather than the effective accomplishment of the WADA Mission' (WADA 2012: 6). ${ }^{8}$ A further aspect of WADA's economic context is the imbalance in wealth between the Agency and many of its subjects (athletes, clubs and ISOs). If a rich athlete or their club challenges a penalty for a doping violation and WADA decides to contest the challenge at the Court of Arbitration for Sport (CAS) the costs to the Agency can be crippling. For example, in 2007 WADA spent around $\$ 1.7 m U S D$ (approximately $7 \%$ of the Agency's annual budget) contesting the appeal by one athlete, Floyd Landis, to CAS against his ban by USADA for doping during the 2006 Tour de France. Interestingly, UCI refused WADA's request to share the cost of defending the USADA decision. Similarly the IOC did not help defray the costs incurred by WADA in undertaking its investigation into doping at the Sochi winter Olympics by passing on to WADA the $\$ 15 \mathrm{~m}$ fine it imposed on Russia following its suspension from the Rio Olympic Games. ${ }^{9}$ Many of the key stakeholders in WADA's economic

\footnotetext{
${ }^{8}$ It remains to be seen whether the 2018 decision to increase contributions by 8\% each year between 2019 and 2022 will be successful.

${ }^{9}$ Russia pays $\$ 15 \mathrm{~m}$ doping fine to Olympic Committee to lift suspension, Moscow Times $22^{\text {nd }}$ Feb. 2018. Available at: https://themoscowtimes.com/news/russia-
} 
environment seem intent on weakening the Agency by gradually undermining its financial capacity.

Apart from scientific and economic aspects of the 10 environment of particular importance is the extent to which the IO can retain its position on the policy agenda of key stakeholders, especially governments. In the 1970s Anthony Downs proposed the idea of an issue attention cycle according to which issues typically progressed through a number of stages: pre-problem stage (awareness of the problem confined to experts with little public/political interest); alarmed discovery and euphoric enthusiasm (usually as a result of a dramatic event which catapults the issue into the media headlines); realization of the costs (and also of the complexity and intractability of the issue); decline in intensity of interest (due to the awareness of costs, boredom or marginalization by more pressing and more amenable issues); and postproblem stage (the issue moves to the political 'back-burner' and is often quietly forgotten and returned to the pre-problem stage of experts). Many global political issues, such as climate change, freedom of expression and gender equity, can be traced through some of these stages and illustrate the challenge of retaining political attention until an issue is adequately addressed. WADA and the issue of doping is a clear illustration of the applicability of the issue attention cycle. For many years doping languished at the pre-problem stage and only moved higher on the global political agenda as a result of scandal - first Ben Johnson's doping violation at the Seoul Olympic Games in 1988 and second the near collapse of the 1998 Tour de France due to doping by the Festina team. The 'alarmed discovery and euphoric enthusiasm' is illustrated by the speed with which ISOs indicated their support for WADA and the Code and the rapidity with which countries ratified the UNESCO Convention Against Doping in Sport. Although the evidence in this paper has amply illustrated the decline in enthusiasm for antidoping and the work of WADA what has prevented doping drifting to the postproblem stage is the recurrence of scandals which re-ignite debate. Without scandals such as that involving Lance Armstrong and the Russian state it may

pays-15-million-doping-fine-to-olympic-committee-lift-suspension-60595. Accessed on: 17th July 2018. 
well have been the case that doping would have drifted towards the postproblem stage. An additional challenge in maintaining momentum within the policy regime is retaining the clarity of definition of the issue of doping. Over the years there have been attempts to situate doping as one element in a wider problem in sport of integrity. There is a logic in linking doping with other ethical issues such as bullying, gender equity, match-fixing and good governance, but whether such links result in a stronger commitment to tackle doping or simply marginalizes the problem is debatable. As noted in the Pound Report (WADA 2012: 4):

Attention is currently being diverted from the need to find a solution to doping in sport ... A new focus has also been put on the matter of match-fixing and corruption, combined with some expression that matchfixing is a far more serious problem than doping, without, apparently, the recognition that doping is very much a subset of the entire problem, but with immediate and visceral impact on a much broader range of the sport population than match-fixing

A final aspect of the political context of WADA, and of all IOs, is the constant calculation by stakeholders of the cost-benefit ratio of their involvement. For many countries, exemplified by Russia, nationalism and the promotion of the national brand change the cost-benefit calculation such that the cost (for example in terms of criticism from WADA) is far outweighed by the perceived benefits accrued from a strong position in the medals table. As President De Gaulle was reputed to have commented when informed of the drug-taking of the French cyclist Jacques Anquetil, 'Doping? What doping? Did he or did he not make them play the Marseillaise [the national anthem] abroad? ${ }^{10} \mathrm{~A}$ related aspect to the attitude of politicians is that of the wider public and the extent to which the objectives and activity of the $\mathrm{IO}$ are considered by the public to be legitimate. A high level of legitimacy is required if IOs are to be effective as 'norm entrepreneurs' on a global level (Finnemore and Sikkink 1998). Legitimacy takes two main forms one moral and the other social: moral legitimacy is based on values and social legitimacy is based on representation

10 Cited L'Équipe Magazine 23 July 1994 
(Davies 2016). With regard to values and doping research demonstrates that on a number of issues, including doping, there is no global value consensus. Value relativism exists on issues such as the rights of the child, the rights of people with disabilities and whaling (Gray 2018, Stoett 1997). Anti-doping values are often heavily mediated by a range of factors including nationalism, wealth, current medical practices and religion (Houlihan et al 2017).

Reference has already been made to the skewed and largely European and North American representation in key WADA committees and boards which leaves much of the sporting world unrepresented and has distinct echoes of cultural colonialism.

\section{Conclusion}

It is argued that the analytical framework outlined in the preceding section enables a rounded and effective assessment of the contribution of WADA to the global anti-doping regime. Specifically it allows an assessment of WADA to be made from two distinct perspectives: the first focuses on its performance and effectiveness in terms of the objectives that it has set for itself or which have been set for it by its principals and primary stakeholders while the second focuses on the performance of WADA in comparison with other similar IOs. If the first approach is adopted then the assessment of WADA is mixed as summarized in Table 1.

Table 1 about here

As can be seen from Table 1 WADA's performance as measured by its use of resources and the ratio of outputs and impact generated to the input of resources is impressive. However, the effectiveness of the organization is more mixed. After the successful launch of the Agency and of the Code and the rapidity with which the Code was adopted as the global reference document for anti-doping policy and action WADA has struggled to maintain momentum. Part of the problem is self-inflicted as WADA has too readily extended its remit beyond Code compliance and into areas, such as 
education and research, where its capacity is more limited. However, by far the major impediment to IO effectiveness has been the largely unsupportive environment in which it has had to operate - an environment which has been, with some notable exceptions, at worst, openly hostile and at best, complacent and passively aggressive. If the performance and effectiveness of WADA is assessed in comparison with other IOs the conclusion is likely to be more positive. An assessment of IOs such as the UN, Oxfam, Save the Children and Greenpeace would produce a similar mixed profile to that shown in Table 1 as all these IOs have experienced significant challenges to their actions and authority in recent years. However, WADA should not draw too much comfort from this more positive comparative assessment as arguably the comparator IOs are addressing much more complex problems than WADA and operating in a much more volatile political and economic environment.

As this analysis shows while WADA undoubtedly operates in a complex, dynamic and far from benign environment the contribution of the Agency to the global anti-doping effort cannot be explained solely by reference to the nature of its environment. There are a number of aspects of the Agency's organization and activities that are more directly under its control and which have the potential to strengthen its leadership role including a clear definition of its role as a regulatory body (i.e. concerned with the maintenance of the Code and the promotion of compliance) and a more balanced global representation on its decision-making bodies. However, any assessment of the operation of WADA over the last twenty years must acknowledge the positive transformation in the global response to the issue of doping in sport and the contribution that the Agency has made.

\section{References}

Abbott, K.W. and Snidal, D. (1998) Why states act through formal international organizations, Journal of Conflict Resolution, 42(1), 3-32. 
Andresen, S. (2007) The effectiveness of UN environmental institutions, International Environmental Agreements: Politics, Law and Economics, 7(4), 317-336.

Barnett, M.N. \& Finnemore, M. (1999) The politics, power and pathologies of international organisations, International Organization, 53(4), 699-732.

Charnovitz, S. (2005) Towards a world environmental organization: Reflections upon a vital debate. In F. Biermann and S. Bauer (eds.) A world environmental organization: Solution or threat for effective international environmental governance, Aldershot: Ashgate, pp. 87-117.

Checkel, J. T. (2005). International institutions and socialization in Europe: Introduction and framework. International organization, 59(4), 801-826.

Cooper, C. (2012) Run, swim, throw, cheat, Biochemical Society, June, 34-39.

Costa, O., \& Jørgensen, K. E. (2012). The influence of international institutions on the EU: a framework for analysis. In The Influence of International Institutions on the EU (pp. 1-22). Palgrave Macmillan, London.

Davies, T.R. (2016) Understanding non-governmental organizations in world politics: The promise and pitfalls of the early 'science of internationalism'. European Journal of International Relations, 23(4), 884-905.

de Hon, O., Kuipers, H., \& van Bottenburg, M. (2015) Prevalence of doping use in elite sports: a review of numbers and methods. Sports Medicine, 45(1), 57-69.

Dembinski, M. (2017) Procedural justice and global order: Explaining African reaction to the application of global protection norms, European Journal of International Relations, 23(4), 809-832. 
Des[ard, M.R. (2017) Can nonprofit capacity be measured? Nonprofit and Voluntary Sector Quarterly, 46(3), 607-626.

Edwards, G.E. (2010) Assessing the effectiveness of human rights nongovernmental organizations from the birth of the United Nations to the $21^{\text {st }}$ century: Ten attributes of highly successful human rights NGOs, Michigan State Journal of International Law, 18(2), 165-228.

Elsig, M. (2010). The World Trade Organization at work: Performance in a member-driven milieu. The Review of International Organizations, 5(3), 345363.

Finnemore, M. and Sikkink, K. (1998) International norm dynamics and political change, International Organization, 52(4), 887-917.

FriedmanT., Rabin, O. \& Frankel, M.S. (2010) Gene doping and sport, Science, 327, 647-8.

Garrett, G.R., Keleman, D. and Schulz, H. (1998) The European Court of Justice, national governments and legal integration in the European Union, International Organization, 52(1), 149-176.

Graham, E.R. (2011) The politics of IO performance: How the interests of donors and 10 staff shape performance in the developing world. Doctoral dissertation, Ohio State University.

Graham, E.R. (2014) International organizations as collective agents: Fragmentation and the limits of principal control at the World Health Organization, European Journal of International Relations, 20(2), 366-90.

Graham, E.R. (201) Money and multilateralism: How funding rules constitute IO governance, International Theory, 7(1), 162-94. 
Gray, S. (2018) Achieving compliance with the World Anti-Doping Code, unpublished $\mathrm{PhD}$ thesis, Loughborough University, Loughborough.

Guardian newspaper (2016) WADA warn Kenya to comply with its anti-doping rules or risk Olympics ban, $23^{\text {rd }}$ Feb 2016. Available at:

https://www.theguardian.com/sport/2016/feb/23/kenya-wada-rio-olympicsban-risk-drugs-in-sport. Accessed; 16th July 2018.

Gutner, T. and Thompson, A. (2010) The politics of IO performance: A framework, Review of International Organizations, 5(3), 227-248.

Hanstad, D. V., Smith, A., \& Waddington, I. (2008). The establishment of the World Anti-Doping Agency: A study of the management of organizational change and unplanned outcomes. International review for the sociology of sport, 43 (3), 227-249.

Hanstad, D. V. (2009). Anti-Doping in Sport. A Study of Policy Development since 1998. Dissertation ved Norwegian School of Sport Sciences, Oslo.

Hanstad, D. V., \& Loland, S. (2009) Elite athletes' duty to provide information on their whereabouts: Justifiable anti-doping work or an indefensible surveillance regime?. European journal of sport science, 9 (1), 3-10.

Hanstad, D. V., Skille, E. Å., \& Loland, S. (2010). Harmonization of antidoping work: Myth or reality?. Sport in society, 13(3), 418-430.

Houlihan, B. (1999) Anti-doping policy in sport: The politics of international policy co-ordination. Public Administration, 77(2), 311-334.

Houlihan, B. (2014). Achieving compliance in international anti-doping policy: An analysis of the 2009 World Anti-Doping Code. Sport management review, 17(3), 265-276. 
Houlihan, B., Downward, P. \& Rasciute, S. (2017) Anti-doping regulations and the significance of public opinion: An analysis of public opinion in Japan and the UK on issues of fairness and integrity in sport, report to the Japanese Anti-Doping Agency, Loughborough: Loughborough University.

House of Commons (2018) Combatting Doping in Sport, 4th Report of Session 2017-19, Digital, Culture, Media and Sport Committee, London: House of Commons.

International Olympic Committee (2017) Decision of the IOC Disciplinary Commission against Alexander Legkov, Lausanne: IOC.

Kaasa, S. (2007) The UN Commission on Sustainable Development: Which mechanisms explain its accomplishments? Global Environmental Politics, 7(3), 107-129.

Kayser, B., Mauron, A., \& Miah, A. (2007). Current anti-doping policy: a critical appraisal. BMC medical ethics, 8(1), 2.

Konovsky, M.A. (2000) Understanding procedural justice and its impact on business organization, Journal of Management, 26(3), 489-511.

Krasner, S. (1983) Regimes and the limits of realism: Regimes as autonomous variables. In International Regimes, ed. S. Krasner, 355-68. Ithaca, NY: Cornell University Press.

Lall, R. (2017) Beyond institutional design: Explaining the performance of Lipson, M. (2010). Performance under ambiguity: international organization performance in UN peacekeeping. The Review of International Organizations, 5(3), 249-284.

March, J. \& Olsen, J.P. (1989) Rediscovering institutions: The organizational basis of politics, New York: Free Press. 
Mazzoni, I., Barroso, O., \& Rabin, O. (2017). Anti-doping challenges with novel psychoactive substances in sport. In Novel Psychoactive Substances (pp. 43-56). Springer, Cham.

Mottram, D. R. (2018). The evolution of doping and anti-doping in sport. In Drugs in sport (pp. 43-60). Routledge.

Niskanen, W.A. 91971) Bureaucracy and representative government, Chicago: Aldine.

Pitsch, W., \& Emrich, E. (2012). The frequency of doping in elite sport: Results of a replication study. International Review for the Sociology of Sport, 47(5), 559-580.

Pollack, M. A., \& Hafner-Burton, E. M. (2010). Mainstreaming international governance: The environment, gender, and IO performance in the European Union. The Review of International Organizations, 5(3), 285-313.

Reuters News Agency (2016) Brazil athletes not dope tested ahead of Rio, $5^{\text {th }}$ August 2016. Available at: https://www.reuters.com/article/us-sport-dopingbrazil-olympics/brazil-athletes-not-dope-tested-ahead-of-rio-reportidUSKCN10G0FZ . Accessed 16th July 2018

Risse, T. (1995). Bringing transnational relations back in: Non-state actors, domestic structures and international institutions(Vol. 42). Cambridge University Press.

Rittberger, V., Zangl, B., \& Kruck, A. (2012). International organization. Macmillan International Higher Education.

Shien, E. (1996) Culture: The missing concept in organizational studies, Administrative Science Quarterly, 41, 229-40. 
Skaset, H. B. (2004). Problems and Prospects of the Anti-Doping Campaign. In John Hoberman \& Verner Møller (eds.), Doping and Public Policy, Odense: University Press of Southern Denmark, pp. 91-100.

Stoett, P. J. (1997) The international politics of whaling. Vancouver: UBC Press.

Stokke, O., and Hønneland, G. eds. (2007). International Cooperation and Arctic Governance: Regime Effectiveness and Northern Region Building. London: Routledge.

Striegel, H., Ulrich, U. and Simon, P. (2010) Randomized response estimates for doping and illicit drug use in elite athletes, Drug and Alcohol Dependence, $106,230-232$.

Stubbe, J. H., Chorus, A. M., Frank, L. E., Hon, O., \& Heijden, P. G. (2014). Prevalence of use of performance enhancing drugs by fitness centre members. Drug testing and analysis, 6(5), 434-438.

Tallberg, J., Sommerer, T., Squatrito, T., \& Lundgren, M. (2016). The performance of international organizations: a policy output approach. Journal of European Public Policy, 23(7), 1077-1096.

Thibaut, J. and Walker, L. (1975) Procedural justice, Hillsdale, NJ: Erlbaum.

Vatterodt, M. (2008) The implementation of the Paris Declaration on Aid Effectiveness by the United Nations: Progress to date and need for further reforms, Research Report, SSG Sozialwissenschaffen, USB Koln.

WADA (2008) Annual Report 2007, Montreal: WADA

WADA (2011) Independent Observers Report: Pan-American Games, October 2011, Montreal: WADA. 
WADA (2013) Report to the WADA Executive Committee on lack of effectiveness of testing programs (chair R Pound), Montreal: WADA.

WADA (2013) WADA statement on Jamaica, $14^{\text {th }}$ November 2013, Available at: https://www.wada-ama.org/en/media/news/2013-11/wada-statement-onjamaica. Accessed on: 16th July 2018.

WADA (2016) Report of the Independent Observers, Games of the XXXI Olympiad, Rio de Janeiro 2016, Montreal: WADA.

WADA (2017) Annual Report 2016, Montreal: WADA

Wagner, U. (2011) Towards the construction of the World Anti-Dopig Agency: Analysing the approaches of FIFA and the IAAF to doping in sport, European Sport Management Quarterly, 11(5), 445-470.

Wagner, U. \& Petersen, K.M. (2014) The IOC and the doping issue: An institutional discursive approach to organizational identity construction, Sport Management Review, 17(2), 160-173.

Waltz, K.N. (2000) Structural realism after the Cold War, International Security, 25(1), 5-41. 